OPEN ACCESS

Edited by:

Yulia Golub,

University Hospital Carl Gustav Carus,

Germany

Reviewed by:

Robert M. Roth

Geisel School of Medicine,

United States

Alessio Simonetti,

Baylor College of Medicine,

United States

*Correspondence:

Nadine Bernhardt

nadine.bernhardt@uniklinikum-

dresden.de

tORCID:

Nadine Bernhardt orcid.org/0000-0002-3188-8431

Johannes Petzold

orcid.org/0000-0003-4163-9014

Maximilian Pilhatsch

orcid.org/0000-0003-4323-3309

Specialty section:

This article was submitted to

Addictive Disorders,

a section of the journal

Frontiers in Psychiatry

Received: 16 September 2019

Accepted: 05 June 2020

Published: 02 July 2020

Citation:

Bernhardt N, Petzold J,

Groß C, Scheck A, Pooseh S,

Mayer-Pelinski R, Zimmermann US,

Smolka MN and Pilhatsch M (2020)

Neurocognitive Dysfunctions and

Their Therapeutic Modulation in

Patients With Methamphetamine

Dependence: A Pilot Study.

Front. Psychiatry 11:581.

doi: 10.3389/fpsyt.2020.00581

\section{Neurocognitive Dysfunctions and Their Therapeutic Modulation in Patients With Methamphetamine Dependence: A Pilot Study}

\author{
Nadine Bernhardt ${ }^{1 * \dagger}$, Johannes Petzold ${ }^{1 \dagger}$, Cornelius Groß ${ }^{1}$, Anna Scheck ${ }^{1}$, \\ Shakoor Pooseh ${ }^{2}$, René Mayer-Pelinski ${ }^{1}$, Ulrich S. Zimmermann ${ }^{1,3}$, Michael N. Smolka ${ }^{1}$ \\ and Maximilian Pilhatsch ${ }^{1,4 t}$

\begin{abstract}
${ }^{1}$ Department of Psychiatry and Psychotherapy, Technische Universität Dresden, Dresden, Germany, ${ }^{2}$ Freiburg Center for Data Analysis and Modeling, Albert-Ludwigs-Universität Freiburg, Freiburg, Germany, ${ }^{3}$ Department of Addiction Medicine and Psychotherapy, Isar-Amper-Klinikum München-Ost, Haar, Germany, ${ }^{4}$ Department of Psychiatry and Psychotherapy, Elblandklinikum Radebeul, Radebeul, Germany
\end{abstract}

Aim: Methamphetamine (MA) abuse and dependence are increasing worldwide and are commonly associated with cognitive deficits. Some studies indicate that such impairments can improve if users become abstinent, but overall results remain inconclusive. Hence, we have performed a longitudinal case-control study investigating key surrogates for attention and impulsive decision-making before and after treatment.

Methods: Thirty patients with MA dependence and 24 non-substance-abusing control participants were recruited. Groups were matched on age, sex and education. All subjects performed a baseline assessment to obtain neurocognitive measures of sustained attention and delay discounting. Patients subsequently participated in an MA-specific relapse prevention program including repeated monitoring of relapse status. After 3 months, participants of both groups were reevaluated for neurocognitive performance.

Results: At baseline, MA patients showed a significantly higher number of omissions compared to controls, indicative of lower sustained attention. Interestingly, we observed a steep decrease of omissions in MA patients to control-group level post treatment. On the other hand, MA patients discounted delayed rewards significantly stronger than controls, indicating a more impulsive choice behavior both before and after treatment.

Limitation: The results should be interpreted with care because of the small sample and short follow-up period.

Conclusion: Our data support earlier findings on partial recovery of cognitive deficits in MA patients. They also strengthen the indication for recently recommended psychotherapeutic interventions and may provide a behavioral monitoring tool to inform treatment progress.

Keywords: methamphetamine, crystal meth, sustained attention, delay discounting, psychotherapy 


\section{INTRODUCTION}

Methamphetamine (MA) also called "crystal meth" is a psychostimulant, whose use has become increasingly popular in several European countries (1). This development reflects its comparably low costs and highly addictive properties. MA abuse and dependence are associated with numerous adverse consequences, which are of great public concern. For example, MA users are more likely unemployed and experience a number of interpersonal difficulties (2). Furthermore, MA users are at high risk for mental and physical health conditions, including depression, anxiety, psychosis, suicide, sexually transmitted diseases and cardiovascular complications (3-5). Consequently, doctors and staff in hospitals, private practices and addiction treatment centers encounter increasing numbers of subjects who suffer from severe complications of MA use. The growing prevalence of MA dependence in Germany prompted the federal government to initiate the development of MA-specific treatment guidelines (6). The areas that are most affected include parts of Saxony, Thuringia and Bavaria. Pharmacotherapy has shown limited effectiveness, making psychotherapeutic interventions the treatment of choice (7). These include cognitive behavioral therapy, motivational interviewing and contingency management, which aim to reduce drug use, positive urine samples and craving. However, such recommendations vastly rely on the transfer of knowledge from overseas and may not be representative of the specific characteristics that are experienced locally. This is especially relevant when mechanistic aspects are not yet fully clarified, which include above all cognitive dysfunctions in MA users and their course under therapy. As such more research is urgently needed to strengthen the evidence for the recommended psychotherapeutic interventions and optimization of care (8).

Compared with other stimulants, MA has a more lipophilic structure and a very long half-life of $8-13 \mathrm{~h}$, causing a fast onset and long duration of action in the brain (9). Besides the resulting highly addictive potential through the acute modulation of the monoaminergic system (10), long-term MA exposure produces persistent damage to dopamine and serotonin release in nerve terminals and triggers gliosis and apoptosis (11). Moreover, chronic MA abuse is associated with abnormalities in brain structure, metabolism and functions, predominantly within the frontostriatal and limbic systems (12). Such changes reflect cognitive impairments $(13,14)$ with pronounced alterations in multiple aspects of attentional control, working memory and executive functions including decision-making (15-19). Clinically, MA-dependent individuals appear distractible and exhibit difficulties in sustaining attention. The ability to keep one's mind continuously focused is considered a fundamental dimension of attentional control with relevance to higher cognitive processes (20). Chronic MA abusers generally show poorer performance than controls on several attention tasks [(18), e.g. CPT and Stroop tasks $(19,21,22)]$, linked to MAassociated neuronal damage and network activity in the cingulate and insular cortices (23). Another cognitive domain altered in MA-dependent individuals is impulsive choice behavior with higher rates of delay discounting relative to controls, i.e., the propensity to select an immediate reward at the expense of a greater future reward (24-28). Overly steep discounting is consistently correlated with a range of conditions, including various drug addictions, obesity and schizophrenia (29-32), and suggested to play a causal role in upholding maladaptive behaviors (continued drug taking despite positive long-term outcome of abstinence, e.g., treatment, health, social). Delay discounting in MA abuse is associated with prefrontal inefficiency, an indication of more automatic and diminished deliberate decision-making processes (e.g. habitual response to a cue signaling drug availability) (24). Such impairments in attention and decision-making may thus critically undermine the individual's efforts to stop or reduce MA use, thereby negatively affecting the outcome of treatment including cognitive behavioral strategies. Indeed, a higher number of omissions of target stimuli in attention tasks has been found to predict relapse among recently abstinent MA-dependent patients $(33,34)$. While maladaptive decision-making has been shown to predict dropout (34), altered neural activity during decision-making may predict relapse (35).

Despite considerable research on adverse functional consequences of chronic MA use and their importance for successful long-term treatment outcomes, the extent to which these problems persist following periods of abstinence remains controversial. Impairments associated with MA use tend to improve with increasing abstinence duration (36-38). The amelioration of cognitive deficits has been shown for short intervals of several weeks (39-41) including attention (42), while other studies have demonstrated that the reinstatement of especially dopamine signaling and associated cognitive functioning may take months to years $(16,36,43,44)$. Moreover, it is still debated whether some of the MA-induced cognitive deficits may be irreversible [e.g. (45)].

The aim of this study was to examine sustained attention and impulsive decision-making in MA-dependent patients and the changes in these domains following a new standardized psychotherapeutic intervention. In addition, we included a healthy comparison sample to help distinguish actual improvement in neuropsychological functioning over time from practice effects. Consistent with previous evidence for partial neurobiological, neuropsychological and psychiatric recovery following treatment of MA-dependent individuals, we hypothesized that sustained attention would improve over a 3-month period while more temporally stable individual characteristics of impulsive choice (46-48) would remain unaltered.

\section{METHODS}

\section{Participants}

Patients were recruited at the University Hospital Dresden. Study inclusion criteria for MA patients were 18-65 years of age; meeting the diagnostic criteria for MA abuse or dependence according to the International Classification of Diseases (ICD- 
10); abstinence from illicit drug use for at least 2 days, proven with negative urine screening results for MA, amphetamines, MDMA, opioids, and THC. Exclusion criteria were any medical conditions, e.g. schizophrenia, severe depressive episodes or limited physical mobility, interfering with the capability to attend group therapy. The assessment of psychiatric comorbidities was supported by a standardized interview using the M.I.N.I. International Neuropsychiatric Interview (49). In addition, non-substance-abusing control subjects (HC) matched for age, sex, and education were recruited via advertisements placed on local community-based websites, which offered employment and volunteer opportunities. HC participants were required to have no lifetime experience with any kind of stimulant (MA, amphetamines, MDMA, methylphenidate, cocaine, etc.) and to have never been diagnosed with drug addiction or suspected of having a substance use disorder. Moreover, the presence or history of any psychiatric disease was excluded by applying a standardized questionnaire (including questions such as, "Have you ever been diagnosed with any mental illness?"). In cases of doubt, a psychiatrist was consulted. The final sample consisted of $30 \mathrm{MA}$-dependent patients (Figure 1) and $24 \mathrm{HC}$ subjects. All participants provided written informed consent and received a compensation between 50 and $90 €$. The study was approved by the local ethics committee of the Technische Universität Dresden and carried out in accordance with the Declaration of Helsinki.

\section{Study Design}

Research staff independent of the relapse prevention program conducted the study recruitment as well as baseline (T1) and follow-up (T2) assessments. Assessments comprised a standardized interview to collect socio-demographic information such as age, sex, partnership, migration status, number of children, school, and vocational qualifications as well as current employment status. Participants of both groups then completed a neuropsychological assessment, which encompassed sustained attention and delay discounting as key surrogates for executive function and impulsive decision-making, respectively. After 3 months, subjects completed a follow-up with the same neuropsychological assessment (Figure 1A).

\section{Treatment}

In- and outpatients were enrolled in our MA-specific relapse prevention program, which is an adaption of the manual by (50) and has demonstrated good feasibility (51) and effectiveness (52) in daily clinical routine. Up to six participants attended 15 twicea-week group sessions, which lasted $50 \mathrm{~min}$. Sessions were conducted by a psychologist, and the treatment method was based on motivational interviewing. The program's progress and goals emphasized on determining high-risk situations for MA use, providing skills to resolve personal, social and environmental barriers, and enhancing coping methods to prevent relapse. Before the first module, one individual session
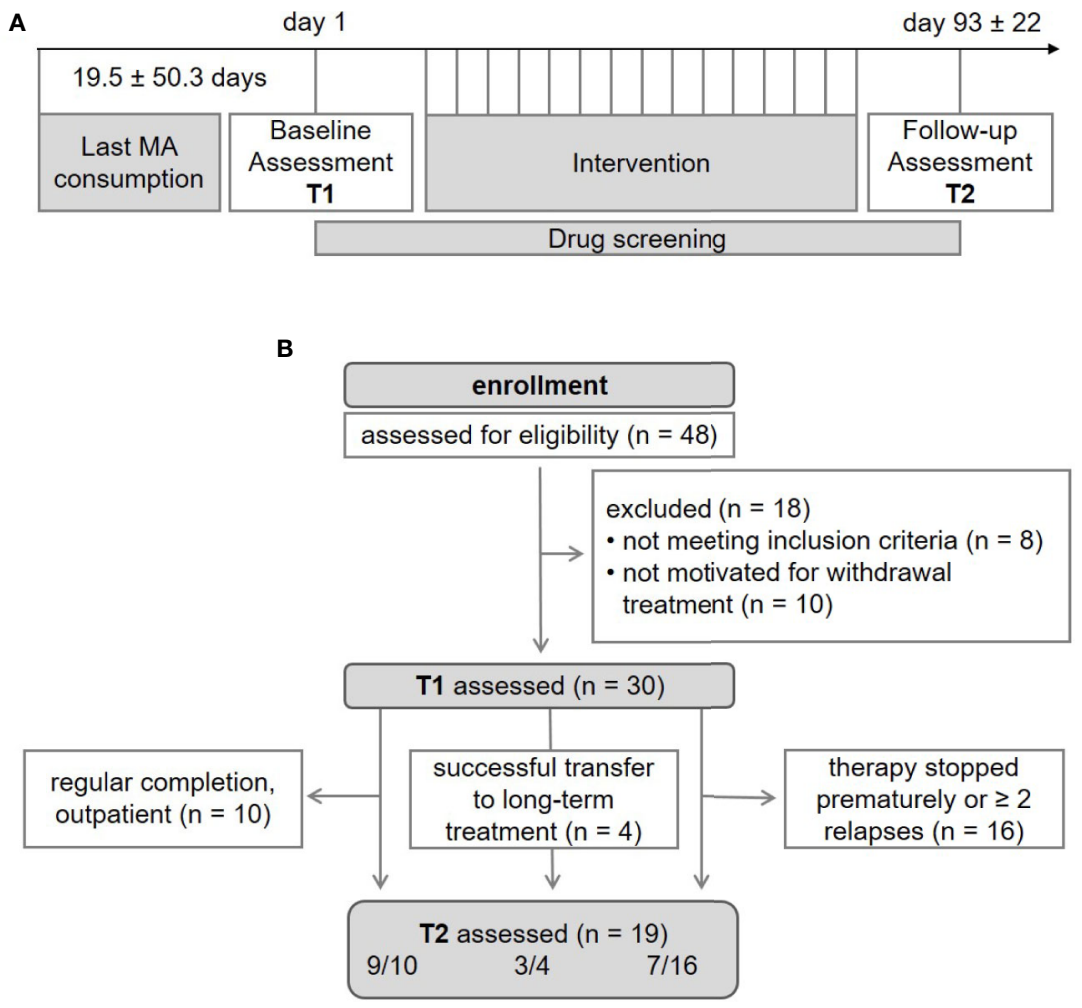

FIGURE 1 | Study overview, recruitment details and sample size of methamphetamine (MA) patients throughout the study process. T1, baseline assessment; T2, follow-up assessment. 
took place in which information about the group program and rules was provided, and the willingness to participate was discussed. In detail, the following topics were covered: "Explanation of the Therapeutic Rational" (module 1), "Motivational Clarification" (modules 2 and 6, if necessary repeated throughout therapy), "Craving" (3-5; psychoeducation, identification of triggers, strategies), "Social Risk Situations" (7-9; dealing with social risk situations, rejection training in role plays), "Apparently Harmless Decisions" (10 and 11, psychoeducation and dealing with seemingly harmless decisions), "Personal Risk Situations" (12 and 13, dealing with personal risk situations), "Emergency Plan" (14, preparation of an emergency plan with strategies for coping with high-risk situations), "Change Plan" (15, coping with problems after the end of therapy).

Inpatients provided weekly urine samples. Outpatients were also called unannounced, but randomized in the morning between Monday and Friday with a probability of $1 / 6$ and ordered to provide urine for drug screening. Urine sample delivery took place under personal observation. In addition, manipulations were made more difficult by measuring the urine temperature immediately after delivery. Samples were quantitatively analyzed at the Institute of Legal Medicine at the Technische Universität Dresden and a sum of $300 \mathrm{ng} / \mathrm{ml}$ for MA and amphetamines was set as a cut-off for a positive result. Relapse was defined as any positive urine result during the course of treatment.

Treatment was classified as "successful" if the patient was enrolled in a postacute management program or attended at least 8 of 15 group therapy sessions. In addition, maximum one MA relapse until T2 indicated by negative drug tests was allowed, provided the relapse was admitted and self-critically processed. If the therapy was prematurely terminated without following specific long-term treatment or if two relapses occurred, treatment was classified as "unsuccessful". "Retention rate" was assessed as the quotient between number of successful treatment and total number of patients completing $\mathrm{T} 1$.

\section{Tasks and Measures \\ Clinical Data}

At T1, MA usage patterns were assessed, which included age of first MA use, total duration of MA use and days of abstinence. Psychiatric comorbidities were recorded according to ICD-10 criteria. A positive family history for the presence of mental disorders in $1^{\text {st }}$ and $2^{\text {nd }}$ degree relatives was systematically inquired according to (53).

\section{Sustained Attention}

The sustained attention subtest (SA) of the reliable and valid computer-administered test of Attentional Performance 2.3.1 (54) was used, which takes approximately $15 \mathrm{~min}$. Participants were rapidly presented with individual symbols varying in shape, size, and filling (e.g. a small triangle and a large circle) and asked to press a key if a symbol matched the shape of the symbol presented immediately before. Omissions were recorded as dependent measures, with higher scores reflecting poorer sustained attention (34). Further variables recorded included the number of incorrect answers (errors) and response times.

\section{Impulsive Choice}

We used a delay discounting task (DD) in which participants repeatedly needed to choose a smaller immediate amount of money or a greater delayed one (e.g. $2 €$ now or $8 €$ in 1 week). Offers were randomly displayed on the left or right side of the screen. There was no time limit for making decisions. To ensure realistic choices and increase task relevance, subjects were informed that at the end of the experiment, one trial would be selected randomly and paid according to the given choice. Monetary rewards ranged from 0.30 to $10 €$. The subjective evaluation of the offers has been described by a hyperbolic function [e.g. (55)]: $\mathrm{V}=\mathrm{A} /(1+k \mathrm{~d})$, where $\mathrm{V}$ represents the subjective value of the amount $\mathrm{A}$ after a delay $\mathrm{d}(3,7,14,31,61$, 180 , or 365 days) and $k$ is a free parameter representing the discount rate. Larger $k$ values represent preference for immediate amounts, which has been interpreted as impulsive choice behavior. To provide behavioral estimates, an adaptive procedure for binary choice presentation was used. For a detailed description of the mathematical framework see (56) and for an application of the task in a clinical cohort of patients with alcohol use disorder see (32). Briefly, a trial-by-trial adaptive approach was chosen to present participants with choice options near their individual indifference point at each trial, thus allowing for fast assessment of individual parameters of behavior. The likelihood of choosing between the two offers followed a softmax probability function: $P(a 1 \mid k, \beta)=1 /(1+$ $\exp [\beta(V 2-V 1)])$, where V1 and V2 are the subjective values of the offers and $\beta>0$ serves as a consistency parameter. The algorithm started from liberal prior distributions on the parameters and, after observing a choice at each trial, updates the belief about the parameters using the Bayes' rule: $P(k, \beta \mid$ choice $) \propto P(k, \beta \mid$ choice $) P(\mathrm{k}, \beta)$. The procedure continued for 50 trials and the estimates at the final trial were considered the best-fitting parameters for a participant. The distribution of parameter estimates over task progression was plotted and found to converge well, yielding stable final estimates of choice behavior (Supplementary Figure 1). Recorded variables included: $\log [k]$ as an estimate of discounting behavior, $\log [\beta]$ as a measure of consistency of choice behavior and for each trial the time to make a decision.

\section{Data Analysis}

Data were initially analyzed with SPSS version 25. Histograms, box plots, and Shapiro tests were employed to judge parameter distribution. Differences between groups in sociodemographic and cognitive variables were evaluated using appropriate parametric or nonparametric tests comparing two independent groups as specified in Tables $\mathbf{1}$ and 2. Logistic regression analyses with forward stepwise selection was used for outcome prediction in MA patients as previously described (52). Individual median response times over all trials were used for group-wise analysis. Longitudinal analyses of pre- and posttreatment cognitive assessments were conducted using $\mathrm{R}$ 3.2.3 (R Development Core Team, 2015). We used mixedeffects models (lmer, R-package: lme4); for DD: prediction of $\log [\mathrm{k}]$ out of time, group and their interaction; for SA: 
TABLE 1 | Socio-demographic and clinical data at T1 and T2.

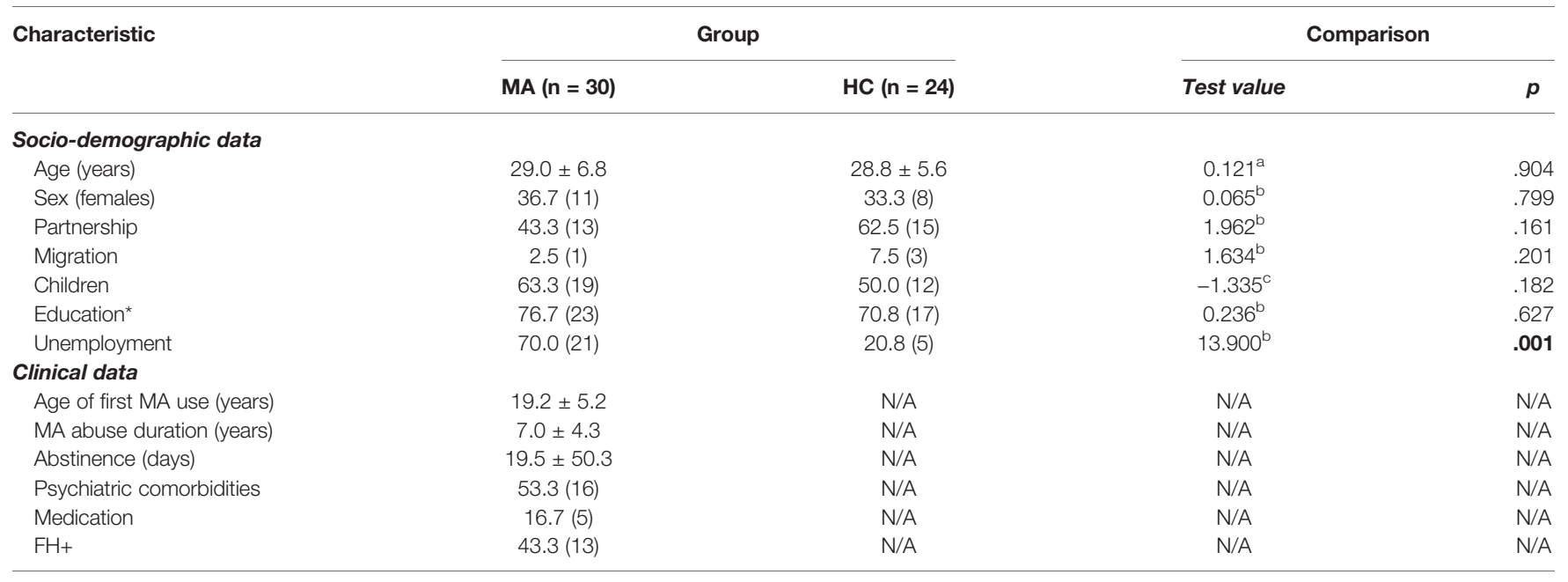

Descriptive statistics (mean $\pm S D$ or \% (N)) and results of group differences. MA, methamphetamine patients; HC, healthy controls; FH+, positive family history for psychiatric disorders according to first-degree relatives.

*secondary school or lower.

at (paired t-test).

${ }^{b}$ Pearson chi-square (exact chi-square test).

${ }^{c} Z$ (Wilcoxon matched pairs rank sum test).

In bold: significant at $p<0.05$.

prediction of omissions out of time, group and their interactions. Following, we assessed the effect of comorbidity on the results found using mixed-effects models including the factors time and the presence/absence of an additional psychiatric disorder. We report estimates, standard deviations, t-values and p-values derived using Satterthwaite approximations. An alpha level of 0.05 was set for the determination of statistical significance.

\section{RESULTS}

\section{Sample Description}

Socio-demographic and clinical characteristics of patients and controls are summarized in Table 1. Statistical analyses showed no significant difference in age, sex and education. However, unemployment was significantly more frequent in MA patients as expected. Fifty-three percent $(n=16)$ of participants with MA

TABLE 2 | Summary statistics of experimental parameters.

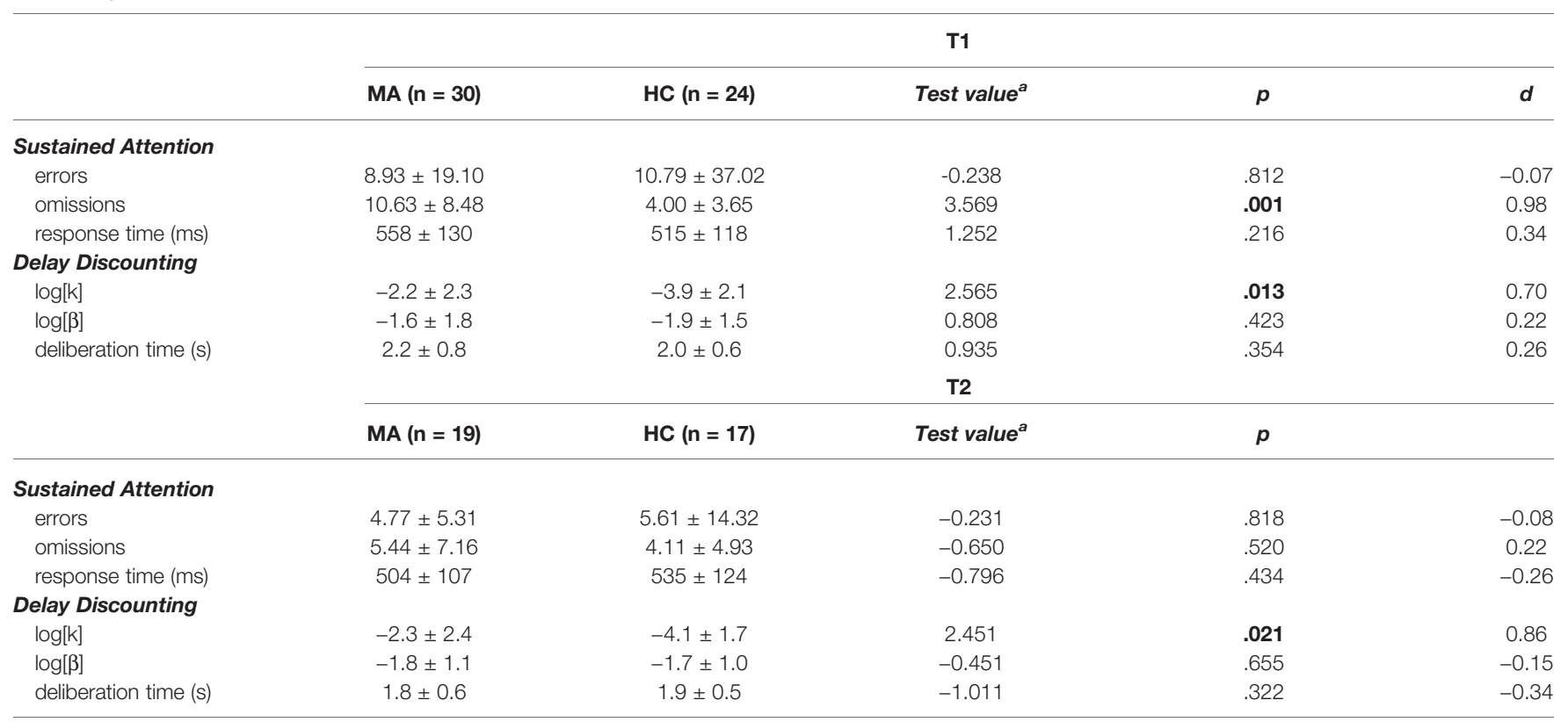

MA, methamphetamine patients; $H C$, healthy controls; $d$, Cohen's $d$; log[k], discounting parameter; log[ $\beta]$, consistency parameter.

${ }^{a} t$ (paired t-test).

In bold: significant at $p<0.05$. 
dependence did present psychiatric comorbidities at the time of treatment: five suffered from unipolar depression, two from attention deficit hyperactivity disorder (ADHD), three had drug-induced psychosis before the start of the study, and one patient had posttraumatic stress disorder and dissocial personality disorder. One patient had ADHD combined with a borderline personality disorder. One patient was diagnosed with three comorbidities: ADHD, a unipolar moderate depressive episode and a borderline personality disorder. Of these 16 comorbid patients, five additionally showed a harmful use of cannabinoids and four an alcohol dependence. Five (16.7\%) patients were prescribed regular psychotropic medication during the study period: one patient received doxepin, one patient sertraline, one patient olanzapine, one patient a combination treatment of duloxetine and quetiapine, and one patient methylphenidate. Clinically, none of these patients were significantly affected by the medication.

\section{Outcome at Follow-Up}

T2 data were obtained from $70 \%(n=17)$ of $\mathrm{HC}$ and $63.3 \%(\mathrm{n}=$ 19) of MA patients initially included. Treatment outcome and participant characteristics of the extended MA patients sample (successful vs. unsuccessful) are reported elsewhere (52). Measures in our subsample (one patient diagnosed with schizophrenia excluded) were comparable. In summary, the treatment was classified as successful in 14 of 30 patients (46.6\%). Four of these patients were transferred to a specific long-term treatment and 10 patients into a specific postacute outpatient treatment setting at our department. By contrast, the treatment was considered not successful in 16 cases, i.e., patients had more than one relapse with MA during the study or prematurely terminated the program (Figure 1B).
Correlational analysis showed trend-level significance for longer regular MA use in men across groups $(r=0.359, \mathrm{p}=.051)$. Moreover, patients with an unsuccessful outcome were predominantly male (81.3\%). The abstinence period before baseline (T1) tended to be longer in patients with a favorable outcome $(\mathrm{U}=71.500, \mathrm{z}=-1.693, \mathrm{p}=.093)$, without being significantly correlated with sex $(\rho=-0.100, p=.597)$ or the duration of regular MA use $(\rho=-0.134, p=.479)$ across groups. Among the demographic and clinical variables, the only predictor significantly increasing the odds of a successful outcome was a shorter period of regular $\mathrm{MA}$ use $(\mathrm{OR}=1.342$, CI $95 \%$ for $\mathrm{OR}=$ $1.028-1.753, \mathrm{~b}=0.294, \mathrm{SE}=0.136, \mathrm{p}=.031)$.

\section{Sustained Attention}

Recorded variables and test statistics can be found in Table 2 . There were no differences between groups in the number of incorrect answers (errors) and response times. Analysis of omissions over groups and time points showed a significant effect of time (Estimate $=-4.66, \mathrm{SD}=1.45, \mathrm{t}=-3.22, \mathrm{p}=.003$ ), group (Estimate $=-11.3, \mathrm{SD}=3.31, \mathrm{t}=-3.42, \mathrm{p}=.001$ ) and $\mathrm{a}$ significant interaction effect (Estimate $=4.66, \mathrm{SD}=2.09, \mathrm{t}=2.23$, $\mathrm{p}=.032$ ). At baseline, MA patients had significantly more omissions, indicative of poorer SA. Over time, the patient group showed a steep decline of omissions, while the control group remained on the same level (Figure 2). Analysis of MA patients controlling for comorbidity similarly showed a significant effect of time (Estimate $=-4.35, \mathrm{SD}=1.71, \mathrm{t}=$ $-2.536, \mathrm{p}=.002$ ) but no effect of comorbidity (Estimate $=2.49$, $\mathrm{SD}=2.79, \mathrm{t}=0.892, \mathrm{p}=.379$ ) (Supplementary Fig. 2). Baseline performance in SA did not significantly differ between patients who finished the program and patients who prematurely stopped treatment (Supplementary Fig. 3).

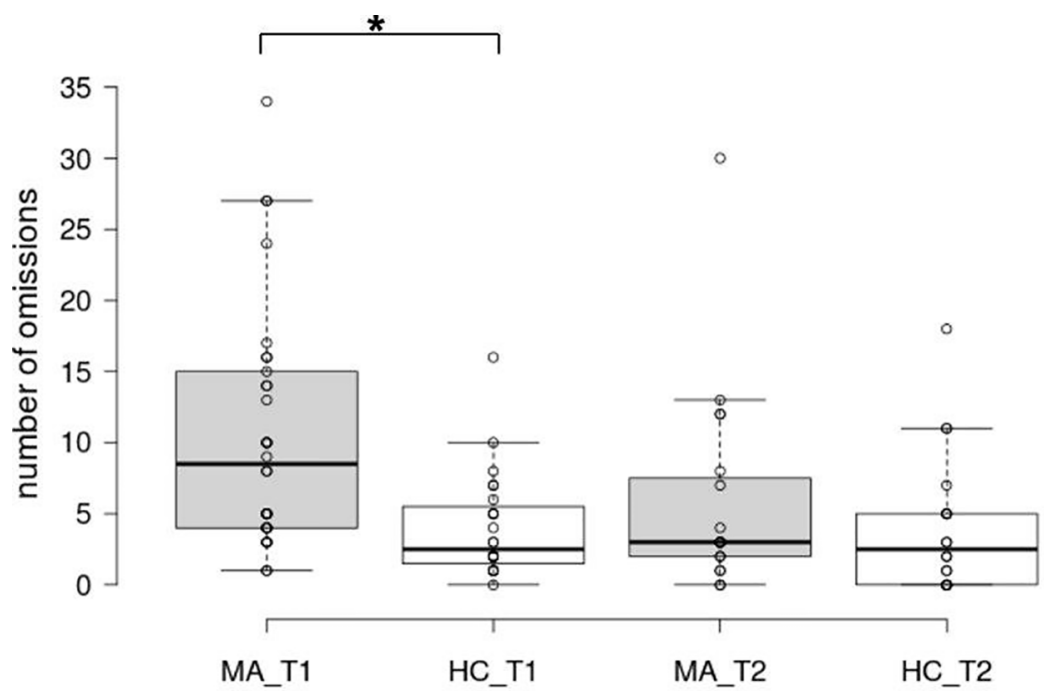

FIGURE 2 | Box plots of omissions in the sustained attention task. The horizontal line represents the median; the boxes extend to the $1^{\text {st }}$ and $3^{\text {rd }}$ quartile, while whiskers extend to the max/min or the corresponding quartile + 1.5 IQR. Additionally, each data point is visualized. MA_T1, MA patients at baseline; HC_T1, control group at baseline; MA_T2, MA patients at follow-up; HC_T2, control group at follow-up; ${ }^{*}$, significant main effect of group. 


\section{Impulsive Choice}

Estimates of choice behavior and deliberation times as well as test statistics can be found in Table 2. Analysis showed a group effect for DD (Estimate $=-2.02, \mathrm{SD}=0.99, \mathrm{t}=-2.04, \mathrm{p}=0.04$ ) with MA patients having significantly higher estimates, indicating that they chose the immediate option more often and thus were more impulsive (Figure 3). For discounting estimates, there was neither a significant change in time from $\mathrm{T} 1$ to $\mathrm{T} 2($ Estimate $=0.11, \mathrm{SD}=0.41, \mathrm{t}=0.26, \mathrm{p}=0.791)$ nor a significant interaction effect (Estimate $=0.42, \mathrm{SD}=0.59, \mathrm{t}=$ $0.71, \mathrm{p}=0.487)$. Analysis of MA patients controlling for comorbidity similarly showed no significant effect of time (Estimate $=0.02, \mathrm{SD}=0.49, \mathrm{t}=0.04, \mathrm{p}=0.973$ ) and comorbidity (Estimate $=0.59, \mathrm{SD}=1.44, \mathrm{t}=0.415, \mathrm{p}=.681$ ). No significant differences between groups were observed for consistency of choices and deliberation times.

\section{DISCUSSION}

The main aim of the present study was to determine whether cognitive impairments in attention and impulsive choice behavior in recently detoxified MA patients recover during a 3-month program, which included psychotherapy and regular drug screening. Our results showed that baseline performances in sustained attention, which were inferior compared with those of controls, improved so much during this period that they were no longer impaired at the follow-up session. In contrast, more impulsive delay discounting in MA patients compared to controls did not change over time.

Baseline differences between groups in both cognitive domains tested in this study are in line with a range of prior studies $(13,22$,
24, 26, 28, 33, 43, 57-59). Thus, attentional deficits and choice behavior favoring immediate rewards are consistently associated with MA use. On the other hand, decision speed of MA patients has been found unaltered previously $(25,60)$ as well as in our sample in which performance demonstrated no group effect. Observed heightened impulsive behaviors may predict drug use or can be a consequence of repeated drug exposure and withdrawal (61). However, impulsivity is a multifaceted construct and impulsive choice behavior might undergo a developmental change that parallels drug consumption as directly observed in rodent studies [e.g. (62)] and suggested from human work in addiction [c.f. (32)]. On the neurobiological level, neurotoxic effects of MA and adaptive changes in the structure of brain regions involved in motivation, reward and the top-down control of behavior may be causal $(21,23$, 27, 63-65). This is complemented by functional magnetic resonance imaging findings of lower activation in the frontal cortices in MA users during attention (66) and decision-making tasks $(24,25,35$, 67), reflective of reduced resources to process information and subsequent performance deficits. In addition, as MA users often lack appetite and therefore stop regular eating, nutritional effects on brain metabolism may also contribute to the observed cognitive dysfunctions (68). Our data thus further support the notion that chronic MA abuse is linked to cognitive dysfunction and may cause cognitive decline $(69,70)$.

Our main finding suggests an improvement of sustained attention performance when compared to levels of control subjects, while performance in controls did not improve over time. Observed effects may be specific to the treatment or represent a subgroup of patients completing treatment. The design of the present study did not include a control group for the intervention. Nevertheless, post hoc analysis showed that baseline performance in sustained attention was not divergent

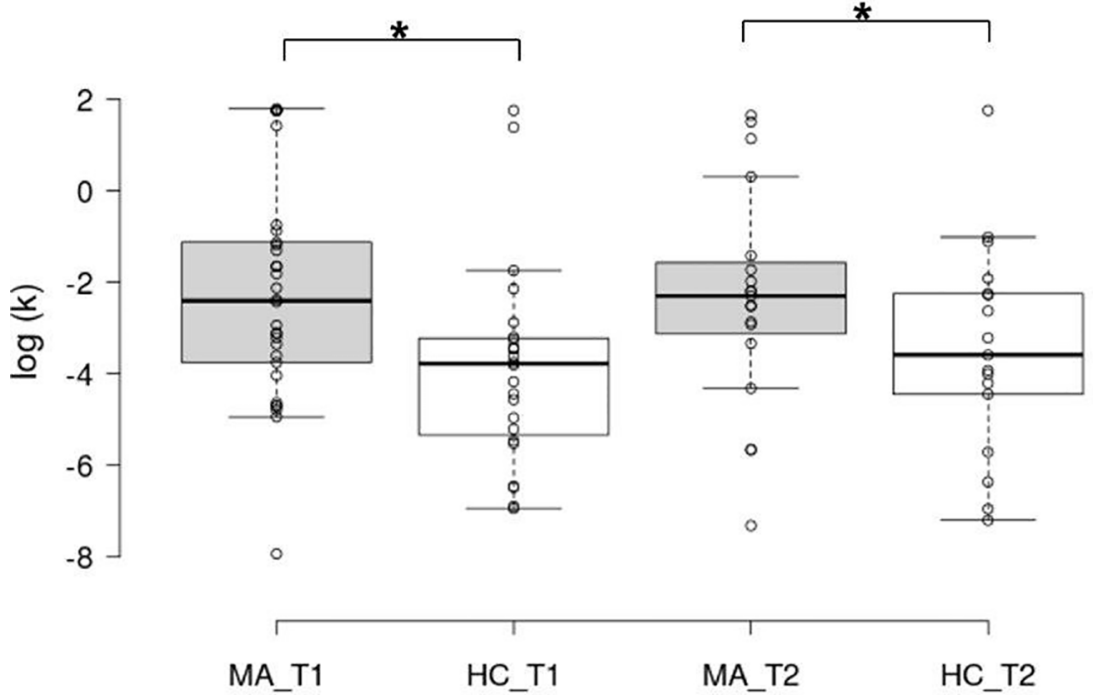

FIGURE 3 | Box plots of the decision-making parameter from the delay discounting task in log scale. The horizontal line represents the median; the boxes extend to the $1^{\text {st }}$ and $3^{\text {rd }}$ quartile, while whiskers extend to the max/min or the corresponding quartile +1.5 IQR. Additionally, each data point is visualized. MA_T1, MA patients at baseline; HC_T1, control group at baseline; MA_T2, MA patients at follow-up; HC_T2, control group at follow-up; *, significant main effect of group. 
between patients who finished the program and those who prematurely stopped treatment, which allows supportive evidence for a treatment effect. This speculation however warrants further assessments. Existing cross-sectional studies already illustrate comparable neuropsychological test performance in MA users and non-MA-using controls following periods of abstinence, i.e. $\geq 8$ months $(16,43,71)$, reflecting that there may indeed be recovery of cognitive functioning following protracted abstinence (38). Other studies evaluating subjects with shorter periods of abstinence ( 5 days to 3 months) report observable deficits in a number of cognitive domains such as attention, episodic memory and executive functions $(39,41)$. Yet, these findings likely align with baseline deficits observed in our study with mean days of abstinence at baseline assessment in the range of these reports. Longitudinal studies that have examined the effects of abstinence on cognitive functioning in MA users when tested in early abstinence and again in later abstinence, similarly yield some evidence for functional recovery. In short observation periods ( $\leq 3$ weeks), MA-dependent individuals have been found to improve their performance on neuropsychological tests including attention (42) and executive functioning (40). Longer periods of abstinence may also improve motor and verbal memory (36, 72). However, these studies did not include a control group for re-test effects, thus limiting conclusions on the causal role of abstinence in performance changes. The inclusion of such a control group clearly represents an important advance of the present study, strengthening our findings of attentional improvements. In support, normalization of global cognitive function in MA-dependent participants after an average of 1 year abstinence from MA has been reported in one study, which also included a control group for longitudinal effects (73).

Finally, relevant to improvements in function, there is evidence for some of the MA-associated changes on the neurobiological level to recover following periods of abstinence. This has been illustrated in human studies for MA-associated brain metabolism and monoamine system abnormalities $(36,40,72,74,75)$ and structural alterations, e.g. prefrontal grey-matter deficit (71). Similar results have been obtained in primate (76) and rodent studies (77). Nonetheless, discordant findings in the literature examining cognitive functions and neurobiological alterations in MA users following abstinence exist [see (23)] and have been discussed to reflect differences, e.g. in study design but also important clinical characteristics such as length of abstinence. Meta-analyses, however, do not imply such an association between length of abstinence and functional impairments in MA users $(58,60)$.

An alternative explanation is provided if not global cognitive function but single performance domains recover over different time scales following periods of abstinence while others may even persist. This idea was put forward together with the notion that neurobiochemical alterations in the monoamine system are likely most pronounced and persistent in e.g. dopamine rich regions (72). In light of the present study this implies that performance in sustained attention, which is highly related to activity measures in the prefrontal cortices (78) and moderately innervated by dopaminergic fibers, follows an early path of recovery, while impulsive choice and decision-making are additionally dependent on high striatal activity (79), the main target of dopamine fibers. This is also in line with the idea of delay discounting representing "more" trait-like features, while sustained attention is highly state-dependent. For discounting to change, conditions must change, and the individual must adapt to the new state, which may take time but may also be drugdependent (80).

\section{Clinical Relevance}

Attentional ability is a critical aspect in processing environmental stimuli during decision-making and highly relevant for long-term treatment success. Pharmacological treatment studies using modafinil or ibudilast have shown some positive effects on the attentional capacity in recently detoxified MA patients $(20,81)$. Our data provide the first evidence that sustained attention can substantially improve during a 3-month MA-specific relapse prevention program based on cognitive behavioral therapy and motivational interviewing. This is in line with available clinical and preclinical evidence suggesting that cognitive stimulation may provide a valuable adjuvant intervention for drug addiction (82). Interestingly, a recent review shows that individual rates of delay discounting can decrease through behavioral training, endorsing context-dependent and changeable attributes in impulsive choice behavior. The most promising avenues in this regard seem to be acceptance-/mindfulness-based trainings and manipulations involving future orientation (83). Thus, we cannot exclude that impulsive choice, which did not normalize after 3 months in our study, would have improved after a longer recovery time or after implementing the aforementioned treatment modules. Although studies are required to identify explicit modules and their mechanisms, interventions that improve such cognitive domains or target activity in relevant networks are promising for the longterm reduction of MA intake and prevention of relapse.

\section{Limitations}

It should be emphasized that this work can only be considered as a pilot study. Firstly, our findings are limited by the relatively small sample size providing low power for within-subject analyses. The small sample size additionally limited analysis to evaluate effects of medication and comorbid diagnoses. The presence of a dual diagnosis in MA users can worsen craving (84) and may thus affect behavior and relapse. While the evaluation of specific comorbid diagnoses was impossible, we could confirm our main results when including the presence/ absence of psychiatric comorbidity in our model. Moreover, the number of cases with medication was too small for systematic investigations on medication effects, which represents a shortcoming as medications have been found to modulate attention performance in patients and animal models $(85,86)$. Secondly, no control group for intervention was included and we thus encourage similar research to address specific intervention effects. Finally, multiple measures are required to inform more rigorously about the nature and degree of deficits in different 
domains of attention and their developmental course under therapy. These include focused, selective, alternating and divided attention in which problems-if they significantly persist into abstinence and recovery-could result in treatment failure and return to regular MA use (87). On the other hand, our study has several strengths, exemplified by the longitudinal HC group and a naturalistic sample of MA patients with comorbid psychiatric disorders and drug abuse histories.

\section{CONCLUSION}

The current study in MA patients shows that sustained attention significantly improved under treatment conditions. Our work thus lends support to the recommended psychotherapeutic interventions. Further measures of sustained attention may even present a valuable tool of parallel clinical monitoring informing treatment progress.

\section{DATA AVAILABILITY STATEMENT}

The datasets generated for this study are available on request to the corresponding author.

\section{ETHICS STATEMENT}

The studies involving human participants were reviewed and approved by the local ethics committee of the Technische Universität Dresden. The patients/participants provided their written informed consent to participate in this study.

\section{REFERENCES}

1. European Monitoring Centre for Drugs and Drug Addiction. European drug report 2016: trends and developments. Luxembourg: Publications Office (2016).

2. Wermuth L. Methamphetamine Use: Hazards and Social Influences. J Drug Educ (2000) 30:423-33. doi: 10.2190/GMH7-3FWX-1AC1-RWXP

3. McKetin R, Lubman DI, Baker AL, Dawe S, Ali RL. Dose-Related Psychotic Symptoms in Chronic Methamphetamine Users: Evidence From a Prospective Longitudinal Study. JAMA Psychiatry (2013) 70:319-24. doi: 10.1001/jamapsychiatry.2013.283

4. Marshall BDL, Werb D. Health outcomes associated with methamphetamine use among young people: a systematic review. Addiction (2010) 105:9911002. doi: 10.1111/j.1360-0443.2010.02932.x

5. Petit A, Karila L, Chalmin F. Methamphetamine Addiction: A Review of the Literature. J Addict Res Ther (2012) S1:006. doi: 10.4172/2155-6105.S1-006

6. Drogenbeauftragte der Bundesregierung, Bundesministerium für Gesundheit (BMG), Bonn, Bundesärztekammer (BÄK) Arbeitsgemeinschaft der deutschen Ärztekammern, Deutsche Gesellschaft für Psychiatrie und Psychotherapie, Psychosomatik und Nervenheilkunde (DGPPN). S3Leitlinie Methamphetamin-bezogene Störungen. Berlin, Heidelberg: Springer Berlin Heidelberg (2017). doi: 10.1007/978-3-662-53541-7.

7. Wodarz N, Krampe-Scheidler A, Christ M, Fleischmann H, Looser W, Schoett K, et al. Evidence-Based Guidelines for the Pharmacological Management of Acute Methamphetamine-Related Disorders and Toxicity. Pharmacopsychiatry (2017) 50:87-95. doi: 10.1055/s-0042-123752

8. Gouzoulis-Mayfrank E, Härtel-Petri R, Hamdorf W, Havemann-Reinecke U, Mühlig S, Wodarz N. Methamphetamine-Related Disorders. Deutsches Aerzteblatt Online (2017) 114:455-61. doi: 10.3238/arztebl.2017.0455

\section{AUTHOR CONTRIBUTIONS}

MP and UZ designed the study. NB, SP, and MS developed the delay discounting task. CG, AS, and MP contributed to study management, data collection and processing. RM-P, NB, JP, and SP analyzed the data. NB, JP, and MP wrote the manuscript. All authors contributed to the article and approved the submitted version.

\section{FUNDING}

This work was funded by the MeDDrive program of the Technische Universität Dresden (MeDDrive grant \#60.401) and the Deutsche Forschungsgemeinschaft (DFG, German Research Foundation) - Project-ID 402170461 - TRR 265 (88). The funding bodies had no further role in the conceptualization of the study, the collection and analysis of data, the preparation of the manuscript or the decision to publish.

\section{ACKNOWLEDGMENTS}

We thank all participants who kindly volunteered to participate in this study.

\section{SUPPLEMENTARY MATERIAL}

The Supplementary Material for this article can be found online at: https://www.frontiersin.org/articles/10.3389/fpsyt.2020. 00581/full\#supplementary-material

9. Volkow ND, Fowler JS, Wang G-J, Shumay E, Telang F, Thanos PK, et al Distribution and pharmacokinetics of methamphetamine in the human body: clinical implications. PloS One (2010) 5:e15269. doi: 10.1371/journal.pone.0015269

10. Sulzer D, Sonders MS, Poulsen NW, Galli A. Mechanisms of neurotransmitter release by amphetamines: A review. Prog Neurobiol (2005) 75:406-33. doi: 10.1016/j.pneurobio.2005.04.003

11. Yu S, Zhu L, Shen Q, Bai X, Di X. Recent Advances in Methamphetamine Neurotoxicity Mechanisms and Its Molecular Pathophysiology. Behav Neurol (2015) 2015:103969. doi: 10.1155/2015/103969

12. Jan RK, Kydd RR, Russell BR. Functional and Structural Brain Changes Associated with Methamphetamine Abuse. Brain Sci (2012) 2:434-82. doi: 10.3390/brainsci2040434

13. Potvin S, Pelletier J, Grot S, Hébert C, Barr AM, Lecomte T. Cognitive deficits in individuals with methamphetamine use disorder: A meta-analysis. Addict Behav (2018) 80:154-60. doi: 10.1016/j.addbeh.2018.01.021

14. Sabrini S, Wang GY, Lin JC, Ian JK, Curley LE. Methamphetamine use and cognitive function: A systematic review of neuroimaging research. Drug Alcohol Depend (2019) 194:75-87. doi: 10.1016/j.drugalcdep.2018.08.041

15. Volkow ND, Chang L, Wang G-J, Fowler JS, Leonido-Yee M, Franceschi D, et al. Association of Dopamine Transporter Reduction With Psychomotor Impairment in Methamphetamine Abusers. AJP (2001) 158:377-82. doi: 10.1176/appi.ajp.158.3.377

16. Chang L, Ernst T, Speck O, Patel H, DeSilva M, Leonido-Yee M, et al. Perfusion MRI and computerized cognitive test abnormalities in abstinent methamphetamine users. Psychiatry Res (2002) 114:65-79. doi: 10.1016/ S0925-4927(02)00004-5

17. Paulus MP, Hozack NE, Zauscher BE, Frank L, Brown GG, Braff DL, et al. Behavioral and functional neuroimaging evidence for prefrontal dysfunction 
in methamphetamine-dependent subjects. Neuropsychopharmacology (2002) 26:53-63. doi: 10.1016/S0893-133X(01)00334-7

18. London ED, Berman SM, Voytek B, Simon SL, Mandelkern MA, Monterosso J, et al. Cerebral Metabolic Dysfunction and Impaired Vigilance in Recently Abstinent Methamphetamine Abusers. Biol Psychiatry (2005) 58:770-8. doi: 10.1016/j.biopsych.2005.04.039

19. Salo R, Nordahl TE, Natsuaki Y, Leamon MH, Galloway GP, Waters C, et al. Attentional Control and Brain Metabolite Levels in Methamphetamine Abusers. Biol Psychiatry (2007) 61:1272-80. doi: 10.1016/j.biopsych.2006.07.031

20. Birath JB, Briones M, Amaya S, Shoptaw S, Swanson A-N, Tsuang J, et al. Ibudilast may improve attention during early abstinence from methamphetamine. Drug Alcohol Depend (2017) 178:386-90. doi: 10.1016/ j.drugalcdep.2017.05.016

21. Salo R, Nordahl TE, Buonocore MH, Natsuaki Y, Waters C, Moore CD, et al. Cognitive control and white matter callosal microstructure in methamphetamine-dependent subjects: a diffusion tensor imaging study. Biol Psychiatry (2009) 65:122-8. doi: 10.1016/j.biopsych.2008.08.004

22. Salo R, Gabay S, Fassbender C, Henik A. Distributed attentional deficits in chronic methamphetamine abusers: evidence from the Attentional Network Task (ANT). Brain Cognit (2011) 77:446-52. doi: 10.1016/j.bandc.2011.08.012

23. London ED, Kohno M, Morales AM, Ballard ME. Chronic methamphetamine abuse and corticostriatal deficits revealed by neuroimaging. Brain Res (2015) 1628:174-85. doi: 10.1016/j.brainres.2014.10.044

24. Monterosso JR, Ainslie G, Xu JS, Cordova X, Domier CP, London ED. Frontoparietal cortical activity of methamphetamine-dependent and comparison subjects performing a delay discounting task. Hum Brain Mapp (2007) 28:383-93. doi: 10.1002/Hbm.20281

25. Hoffman WF, Schwartz DL, Huckans MS, McFarland BH, Meiri G, Stevens $\mathrm{AA}$, et al. Cortical activation during delay discounting in abstinent methamphetamine dependent individuals. Psychopharmacology (2008) 201:183-93. doi: 10.1007/s00213-008-1261-1

26. Schwartz DL, Mitchell AD, Lahna DL, Luber HS, Huckans MS, Mitchell SH, et al. Global and local morphometric differences in recently abstinent methamphetamine-dependent individuals. Neuroimage (2010) 50:1392-401. doi: 10.1016/j.neuroimage.2010.01.056

27. Ballard ME, Mandelkern MA, Monterosso JR, Hsu E, Robertson CL, Ishibashi $\mathrm{K}$, et al. Low Dopamine D2/D3 Receptor Availability is Associated with Steep Discounting of Delayed Rewards in Methamphetamine Dependence. Int J Neuropsychopharmacol (2015) 18:pyul19-9. doi: 10.1093/ijnp/pyul19

28. Yoon JH, Weaver MT, De La Garza R, Suchting R, Nerumalla CS, Omar Y, et al. Comparison of three measurement models of discounting among individuals with methamphetamine use disorder. Am J Addict (2018) 27 (5):425-32. doi: 10.1111/ajad.12761

29. Bickel WK, Jarmolowicz DP, Mueller ET, Koffarnus MN, Gatchalian KM. Excessive discounting of delayed reinforcers as a trans-disease process contributing to addiction and other disease-related vulnerabilities: Emerging evidence. Pharmacol Ther (2012) 134:287-97. doi: 10.1016/j.pharmthera. 2012.02.004

30. Amlung M, Petker T, Jackson J, Balodis I, MacKillop J. Steep discounting of delayed monetary and food rewards in obesity: a meta-analysis. psychol Med (2016) 46:2423-34. doi: 10.1017/S0033291716000866

31. Story GW, Moutoussis M, Dolan RJ. A Computational Analysis of Aberrant Delay Discounting in Psychiatric Disorders. Front Psychol (2016) 6:1948. doi: 10.3389/fpsyg.2015.01948

32. Bernhardt N, Nebe S, Pooseh S, Sebold M, Sommer C, Birkenstock J, et al. Impulsive Decision Making in Young Adult Social Drinkers and Detoxified Alcohol-Dependent Patients: A Cross-Sectional and Longitudinal Study. Alcohol Clin Exp Res (2017) 41:1794-807. doi: 10.1111/acer.13481

33. Clark VP, Beatty GK, Anderson RE, Kodituwakku P, Phillips JP, Lane TDR, et al. Reduced fMRI activity predicts relapse in patients recovering from stimulant dependence: Prediction of Relapse Using fMRI. Hum Brain Mapp (2014) 35:414-28. doi: 10.1002/hbm.22184

34. Chen Y-C, Chen C-K, Wang L-J. Predictors of Relapse and Dropout During a 12-Week Relapse Prevention Program for Methamphetamine Users. J Psychoactive Drugs (2015) 47:317-24. doi: 10.1080/02791072.2015.1071447

35. Paulus MP, Tapert SF, Schuckit MA. Neural activation patterns of methamphetamine-dependent subjects during decision making predict relapse. Arch Gen Psychiatry (2005) 62:761-8. doi: 10.1001/archpsyc.62.7.761
36. Volkow ND, Chang L, Wang G-J, Fowler JS, Franceschi D, Sedler M, et al. Loss of Dopamine Transporters in Methamphetamine Abusers Recovers with Protracted Abstinence. J Neurosci (2001) 21:9414-8. doi: 10.1523/ JNEUROSCI.21-23-09414.2001

37. Hart CL, Marvin CB, Silver R, Smith EE. Is Cognitive Functioning Impaired in Methamphetamine Users? A Critical Review. Neuropsychopharmacol (2012) 37:586-608. doi: 10.1038/npp.2011.276

38. Stock A-K, Rädle M, Beste C. Methamphetamine-associated difficulties in cognitive control allocation may normalize after prolonged abstinence. Prog Neuropsychopharmacol Biol Psychiatry (2019) 88:41-52. doi: 10.1016/ j.pnpbp.2018.06.015

39. Kalechstein AD, Newton TF, Green M. Methamphetamine Dependence Is Associated With Neurocognitive Impairment in the Initial Phases of Abstinence. JNP (2003) 15:215-20. doi: 10.1176/jnp.15.2.215

40. Chou Y-H, Huang W-S, Su T-P, Lu R-B, Wan F-J, Fu Y-K. Dopamine transporters and cognitive function in methamphetamine abuser after a short abstinence: A SPECT study. Eur Neuropsychopharmacol (2007) 17:46-52. doi: 10.1016/j.euroneuro.2006.05.002

41. Simon SL, Dean AC, Cordova X, Monterosso JR, London ED. Methamphetamine dependence and neuropsychological functioning: evaluating change during early abstinence. J Stud Alcohol Drugs (2010) 71:335-44. doi: 10.15288/jsad.2010.71.335

42. Jaffe C, Bush KR, Straits-Troster K, Meredith C, Romwall L, Rosenbaum G, et al. Saxon AJ. A comparison of methamphetamine-dependent inpatients childhood attention deficit hyperactivity disorder symptomatology. J Addict Dis (2005) 24:133-52. doi: 10.1300/J069v24n03_11

43. Salo R, Nordahl TE, Galloway GP, Moore CD, Waters C, Leamon MH. Drug abstinence and cognitive control in methamphetamine-dependent individuals. J Subst Abuse Treat (2009) 37:292-7. doi: 10.1016/j.jsat.2009.03.004

44. Salo R, Buonocore MH, Leamon M, Natsuaki Y, Waters C, Moore CD, et al. Extended findings of brain metabolite normalization in MA-dependent subjects across sustained abstinence: A proton MRS study. Drug Alcohol Depend (2011) 113:133-8. doi: 10.1016/j.drugalcdep.2010.07.015

45. Farhadian M, Akbarfahimi M, Hassani Abharian P, Hosseini SG, Shokri S. Assessment of Executive Functions in Methamphetamine-addicted Individuals: Emphasis on Duration of Addiction and Abstinence. Basic Clin Neurosci (2017) 8:147-53. doi: 10.18869/nirp.bcn.8.2.147

46. Odum AL. Delay discounting: trait variable? Behav Processes (2011) 87:1-9. doi: 10.1016/j.beproc.2011.02.007

47. Green L, Myerson J. How Many Impulsivities? A Discounting Perspective. J Exp Anal Behav (2013) 99:3-13. doi: 10.1002/jeab.1

48. Dennhardt AA, Yurasek AM, Murphy JG. Change in delay discounting and substance reward value following a brief alcohol and drug use intervention. J Exp Anal Behav (2015) 103:125-40. doi: 10.1002/jeab.121

49. Ackenheil M, Stotz G, Dietz-Bauer R. Mini International Neuropsychiatric Interview. German Version 5.0.0, DSM-IV. München: Psychiatrische Universitätsklinik München (1999).

50. Lee N, Johns L, Jenkinson R, Johnston J, Connolly K, Hall K, et al. Methamphetamine dependence and treatment. In: Clinical Treatment Guidelines for Alcohol and Drug Clinicians. Fitzroy, VIC: Turning Point Alcohol and Drug Centre Inc. (2015). p. 35-50.

51. Groß C, Schützwohl M, Mayer-Pelinski R, Hasler H, Kirchner T, Scheck A, et al. CrystalClean - Ein deutschsprachiges Manual zur qualifizierten Entgiftungs- und Motivationsbehandlung bei Crystal Meth-Abhängigkeit Durchführbarkeit und Akzeptanz. Psychiat Prax (2020) 47:22-8. doi: 10.1055/ a-1003-5148

52. Petzold J, Weber B, Bassett TR, Bauer M, Bernhardt N, Groß C, et al. Effectiveness of the First German-Language Group Psychotherapy Manual to Accompany Short-Term Treatment in Methamphetamine Dependence. Front Psychiatry (2020) 11:130. doi: 10.3389/fpsyt.2020.00130

53. Pilhatsch M, Vetter NC, Hübner T, Ripke S, Müller KU, Marxen M, et al. Amygdala-Function Perturbations in Healthy Mid-Adolescents With Familial Liability for Depression. J Am Acad Child Adolesc Psychiatry (2014) 53:559568.e6. doi: 10.1016/j.jaac.2014.02.010

54. Zimmermann P, Fimm B. Zimmermann: Testbatterie zur Erfassung von Aufmerksamkeitsstörungen. Freiburg: Psytest (1993).

55. Mazur JE. Quantitative analysis of behavior: Vol. 5. The effect of delay and of intervening events on reinforcement value. In: Commons ML, Mazur JE, 
Nevin JA, Rachlin H, editors. An adjusting procedure for studying delayed reinforcement Commons. Hillsdale, NJ: Erlbaum (1987). p. 55-73.

56. Pooseh S, Bernhardt N, Guevara A, Huys QJM, Smolka MN. Value-based decision-making battery: A Bayesian adaptive approach to assess impulsive and risky behavior. Behav Res Methods (2018) 50:236-49. doi: 10.3758/ s13428-017-0866-x

57. Hoffman WF, Moore M, Templin R, McFarland B, Hitzemann RJ, Mitchell SH. Neuropsychological function and delay discounting in methamphetamine-dependent individuals. Psychopharmacol (Berl) (2006) 188:162-70. doi: 10.1007/s00213-006-0494-0

58. Scott JC, Woods SP, Matt GE, Meyer RA, Heaton RK, Atkinson JH, et al. Neurocognitive Effects of Methamphetamine: A Critical Review and Metaanalysis. Neuropsychol Rev (2007) 17:275-97. doi: 10.1007/s11065-007-9031-0

59. Fitzpatrick RE, Rubenis AJ, Lubman DI, Verdejo-Garcia A. Cognitive deficits in methamphetamine addiction: Independent contributions of dependence and intelligence. Drug Alcohol Depend (2020) 209:107891. doi: 10.1016/ j.drugalcdep.2020.107891

60. Basterfield C, Hester R, Bowden SC. A meta-analysis of the relationship between abstinence and neuropsychological functioning in methamphetamine use disorder. Neuropsychology (2019) 33(5):739-53. doi: 10.1037/neu0000552

61. Jentsch JD, Ashenhurst JR, Cervantes MC, James AS, Groman SM, Pennington ZT. Dissecting Impulsivity and its Relationships to Drug Addictions. Ann N Y Acad Sci (2014) 1327:1-26. doi: 10.1111/nyas.12388

62. Richards JB, Sabol KE, de Wit H. Effects of methamphetamine on the adjusting amount procedure, a model of impulsive behavior in rats. Psychopharmacology (1999) 146:432-9. doi: 10.1007/PL00005488

63. Robinson TE, Kolb B. Persistent Structural Modifications in Nucleus Accumbens and Prefrontal Cortex Neurons Produced by Previous Experience with Amphetamine. J Neurosci (1997) 17:8491-7. doi: 10.1523/ JNEUROSCI.17-21-08491.1997

64. Robinson TE, Kolb B. Structural plasticity associated with exposure to drugs of abuse. Neuropharmacology (2004) 47:33-46. doi: 10.1016/j.neuropharm. 2004.06.025

65. Lee B, London ED, Poldrack RA, Farahi J, Nacca A, Monterosso JR, et al. Striatal Dopamine D2/D3 Receptor Availability is Reduced in Methamphetamine Dependence and is Linked to Impulsivity. J Neurosci: Off J Soc Neurosci (2009) 29:14734. doi: 10.1523/JNEUROSCI.3765-09.2009

66. Nestor LJ, Ghahremani DG, Monterosso J, London ED. Prefrontal hypoactivation during cognitive control in early abstinent methamphetamine-dependent subjects. Psychiatry Res (2011) 194:287-95. doi: 10.1016/j.pscychresns. 2011.04.010

67. Stewart JL, May AC, Poppa T, Davenport PW, Tapert SF, Paulus MP. You are the danger: attenuated insula response in methamphetamine users during aversive interoceptive decision-making. Drug Alcohol Depend (2014) 142:110-9. doi: 10.1016/j.drugalcdep.2014.06.003

68. Proebstl L, Kamp F, Koller G, Soyka M. Cognitive Deficits in Methamphetamine Users: How Strong is The Evidence? Pharmacopsychiatry (2018) 51:243-50. doi: $10.1055 / \mathrm{s}-0043-123471$

69. Nakama H, Chang L, Fein G, Shimotsu R, Jiang CS, Ernst T. Methamphetamine users show greater than normal age-related cortical gray matter loss. Addiction (2011) 106:1474-83. doi: 10.1111/j.1360-0443.2011.03433.x

70. Dean AC, Groman SM, Morales AM, London ED. An evaluation of the evidence that methamphetamine abuse causes cognitive decline in humans. Neuropsychopharmacology (2013) 38:259-74. doi: 10.1038/npp.2012.179

71. Kim SJ, Lyoo IK, Hwang J, Chung A, Hoon Sung Y, Kim J, et al. Prefrontal greymatter changes in short-term and long-term abstinent methamphetamine abusers. Int J Neuropsychopharmacol (2006) 9:221-8. doi: 10.1017/S1461145705005699

72. Wang G-J, Volkow ND, Chang L, Miller E, Sedler M, Hitzemann R, et al. Fowler JS. Partial recovery of brain metabolism in methamphetamine abusers after protracted abstinence. Am J Psychiatry (2004) 161:242-8. doi: 10.1176/ appi.ajp.161.2.242

73. Iudicello JE, Woods SP, Vigil O, Scott JC, Cherner M, Heaton RK, et al. HIV Neurobehavioral Research Center (HNRC) Group. Longer term improvement in neurocognitive functioning and affective distress among methamphetamine users who achieve stable abstinence. J Clin Exp Neuropsychol (2010) 32:70418. doi: 10.1080/13803390903512637

74. Nordahl TE, Salo R, Natsuaki Y, Galloway GP, Waters C, Moore CD, et al. Methamphetamine Users in Sustained Abstinence: A Proton Magnetic
Resonance Spectroscopy Study. Arch Gen Psychiatry (2005) 62:444-52. doi: 10.1001/archpsyc.62.4.444

75. Boileau I, Rusjan P, Houle S, Wilkins D, Tong J, Selby P, et al. Increased Vesicular Monoamine Transporter Binding during Early Abstinence In Human Methamphetamine Users: Is VMAT2 a Stable Dopamine Neuron Biomarker? J Neurosci (2008) 28:9850-6. doi: 10.1523/JNEUROSCI.3008-08.2008

76. Harvey DC, Lacan G, Tanious SP, Melega WP. Recovery from methamphetamine induced long-term nigrostriatal dopaminergic deficits without substantia nigra cell loss. Brain Res (2000) 871:259-70. doi: 10.1016/s0006-8993(00)02439-2

77. Segal DS, Kuczenski R, O’Neil ML, Melega WP, Cho AK. Prolonged exposure of rats to intravenous methamphetamine: behavioral and neurochemical characterization. Psychopharmacology (2005) 180:501-12. doi: 10.1007/ s00213-005-2188-4

78. Rosenberg MD, Finn ES, Scheinost D, Papademetris X, Shen X, Constable RT. Chun MM. A neuromarker of sustained attention from whole-brain functional connectivity. Nat Neurosci (2016) 19:165-71. doi: 10.1038/nn.4179

79. Kohno M, Morales AM, Ghahremani DG, Hellemann G, London ED. Risky Decision Making, Prefrontal Cortex, and Mesocorticolimbic Functional Connectivity in Methamphetamine Dependence. JAMA Psychiatry (2014) 71:812. doi: 10.1001/jamapsychiatry.2014.399

80. Landes RD, Christensen DR, Bickel WK. Delay Discounting Decreases in Those Completing Treatment for Opioid Dependence. Exp Clin Psychopharmacol (2012) 20:302-9. doi: 10.1037/a0027391

81. Dean AC, Sevak RJ, Monterosso JR, Hellemann G, Sugar CA, London ED. Acute modafinil effects on attention and inhibitory control in methamphetamine-dependent humans. J Stud Alcohol Drugs (2011) 72:94353. doi: $10.15288 /$ jsad.2011.72.943

82. Sampedro-Piquero P, Ladrón de Guevara-Miranda D, Pavón FJ, Serrano A, Suárez J, Rodríguez de Fonseca F, et al. Neuroplastic and cognitive impairment in substance use disorders: a therapeutic potential of cognitive stimulation. Neurosci Biobehav Rev (2018) 106:23-48. doi: 10.1016/ j.neubiorev.2018.11.015

83. Scholten H, Scheres A, de Water E, Graf U, Granic I, Luijten M. Behavioral trainings and manipulations to reduce delay discounting: A systematic review. Psychon Bull Rev (2019) 26:1803-49. doi: 10.3758/s13423-019-01629-2

84. Nakama H, Chang L, Cloak C, Jiang C, Alicata D, Haning W. Association between Psychiatric Symptoms and Craving in Methamphetamine Users. Am J Addict (2008) 17:441-6. doi: 10.1080/10550490802268462

85. Kaskey GB, Salzman LF, Ciccone JR, Klorman R. Effects of lithium on evoked potentials and performance during sustained attention. Psychiatry Res (1980) 3:281-9. doi: 10.1016/0165-1781(80)90058-x

86. Marshall CA, Brodnik ZD, Mortensen OV, Reith MEA, Shumsky JS, Waterhouse $\mathrm{BD}$, et al. Selective activation of Dopamine D3 receptors and norepinephrine transporter blockade enhances sustained attention. Neuropharmacology (2019) 148:178-88. doi: 10.1016/j.neuropharm.2019.01.003

87. Mehrjerdi ZA, Kiakojouri A, Dolan K. Attention problems and cognitivebehavioural therapy for methamphetamine users: Implications for treatment. J Addict Med Ther (2013) 2(1):1006.

88. Heinz A, Kiefer F, Smolka MN, Endrass T, Beste C, Beck A, et al. Addiction Research Consortium: Losing and regaining control over drug intake (ReCoDe)-From trajectories to mechanisms and interventions. Addict Biol (2020) 25:e12866. doi: 10.1111/adb.12866

Conflict of Interest: The authors declare that the research was conducted in the absence of any commercial or financial relationships that could be construed as a potential conflict of interest.

The handling editor declared a shared affiliation, though no other collaboration, with the authors at the time of review.

Copyright (c) 2020 Bernhardt, Petzold, Groß, Scheck, Pooseh, Mayer-Pelinski, Zimmermann, Smolka and Pilhatsch. This is an open-access article distributed under the terms of the Creative Commons Attribution License (CC BY). The use, distribution or reproduction in other forums is permitted, provided the original author(s) and the copyright owner(s) are credited and that the original publication in this journal is cited, in accordance with accepted academic practice. No use, distribution or reproduction is permitted which does not comply with these terms. 